\title{
Different expression of catecholamine transporters in phaeochromocytomas from patients with von Hippel-Lindau syndrome and multiple endocrine neoplasia type 2
}

\author{
Thanh-Truc Huynh, Karel Pacak ${ }^{1}$, Frederieke M Brouwers ${ }^{1}$, Mones S Abu-Asab ${ }^{2}$, Robert A Worrell ${ }^{3}$, \\ MacClellan M Walther ${ }^{3}$, Abdel G Elkahloun ${ }^{4}$, David S Goldstein, Susannah Cleary and Graeme Eisenhofer \\ Clinical Neurocardiology Section, National Institute of Neurological Disorders and Stroke, ${ }^{1}$ Reproductive Biology and Medicine Branch, National Institute \\ of Child Health and Human Development, ${ }^{2}$ Laboratory of Pathology, National Cancer Institute, ${ }^{3}$ Urologic Oncology Branch, National Cancer Institute and \\ ${ }^{4}$ Genome Technology Branch, National Human Genome Research Institute, National Institutes of Health, Bethesda, Maryland, USA
}

(Correspondence should be addressed to G Eisenhofer, Building 10, Room 6N252 National Institutes of Health 10 CENTER DR, MSC-1620 Bethesda, Maryland 20892,USA; Email: ge@box-g.nih.gov)

\begin{abstract}
Objective: Phaeochromocytomas in patients with multiple endocrine neoplasia type 2 (MEN 2) produce adrenaline, whereas those with von Hippel-Lindau (VHL) syndrome do not. This study assessed whether these distinctions relate to differences in expression of the transporters responsible for uptake and storage of catecholamines - the noradrenaline transporter and the vesicular monoamine transporters (VMAT 1 and VMAT 2).

Methods: Tumour tissue and plasma samples were obtained from 31 patients with hereditary phaeochromocytoma -18 with VHL syndrome and 13 with MEN 2. We used quantitative PCR, Western blotting, electron microscopy, immunohistochemistry and measurements of plasma and tumour catecholamines to assess differences in expression of the transporters in noradrenaline-producing vs adrenaline-producing hereditary tumours. These differences were compared with those in a further group of 26 patients with non-syndromic phaeochromocytoma.

Results: Adrenaline-producing phaeochromocytomas in MEN 2 patients expressed more noradrenaline transporter mRNA and protein than noradrenaline-producing tumours in VHL patients. In contrast, there was greater expression of VMAT 1 in VHL than MEN 2 tumours, while expression of VMAT 2 did not differ significantly. These differences were associated with larger numbers of storage vesicles and higher tissue contents of catecholamines in MEN 2 than in VHL tumours. Differences in expression of the noradrenaline transporter were weaker, and those of VMAT 1 and VMAT 2 stronger, in noradrenaline and adrenaline-producing non-syndromic than in hereditary tumours. Conclusions: The findings show that, in addition to differences in catecholamine biosynthesis, phaeochromocytomas in MEN 2 and VHL syndrome also differ in expression of the transporters responsible for uptake and vesicular storage of catecholamines.
\end{abstract}

European Journal of Endocrinology 153 551-563

\section{Introduction}

Phaeochromocytomas are rare endocrine tumours with diverse phenotypes and highly variable clinical presentations but with the common feature that they synthesize, store, release, and metabolize catecholamines. Mutations affecting 5 different genes are associated with a sizeable proportion of the tumours $(1,2)$.

Multiple endocrine neoplasia type 2 (MEN 2), caused by mutations of the RET protooncogene, and von Hippel-Lindau (VHL) syndrome, due to mutations of the VHL tumour suppressor gene, are two of the more well characterized familial syndromes associated with a predisposition to phaeochromocytoma. Phaeochromocytomas in these two conditions have distinctive patterns of gene expression, indicating different pathways of tumourigenesis and explaining different phenotypic features of the tumours (3). Phaeochromocytomas in MEN 2 express phenylethanolamine Nmethyltransferase (PNMT), the enzyme that converts noradrenaline to adrenaline, whereas tumours in VHL syndrome do not express PNMT (4). As a consequence, synthesis of noradrenaline and adrenaline and metabolism to normetanephrine and metanephrine characterize the former tumours, whereas synthesis of noradrenaline and metabolism to normetanephrine characterize the latter (5). Phaeochromocytomas in 
VHL syndrome and MEN 2 also differ in the characteristics of catecholamine release $(4,6)$, but whether there may be associated differences in catecholamine uptake and storage is not established.

Previous studies indicated differences in expression of the cell membrane noradrenaline transporter and vesicular monoamine transporters (VMAT 1 and VMAT 2) in noradrenaline-and adrenaline-producing chromaffin cells or neurons (7-9). On the basis of these observations, we hypothesized that the expression profiles of catecholamine transporters in noradrenaline-producing phaeochromocytomas in VHL patients would differ from those in adrenaline-producing tumours in MEN 2 patients. The present study characterized expression of catecholamine transporters in phaeochromocytomas in the two hereditary syndromes.

\section{Materials and methods}

\section{Patients}

The study included 31 patients with hereditary phaeochromocytoma, 13 with the tumour due to MEN 2 and 18 due to VHL syndrome (Table 1). An additional 26 patients with phaeochromocytoma, in whom there was no evidence of a hereditary syndrome, were also included for comparison purposes. The 57 patients were selected from a larger group of 275 patients with phaeochromocytoma, who were initially tested for the tumour using biochemical tests carried out at the National Institutes of Health (NIH) in the 10-year period between 1994 and 2004. Inclusion into the study groups here depended on availability of good quality samples of tumour tissue for analyses of gene and protein expression. Blood and tumour tissue samples were obtained under studies approved by an appropriate Institutional Review Board (IRB), with informed consent from patients.

The diagnosis of MEN 2 or VHL syndrome in the 31 patients with hereditary phaeochromocytoma was confirmed by identification of germline mutations of the RET protooncogene or the VHL tumour suppressor gene. Four of the 18 VHL patients were related, including two brothers in one family and a brother and a sister in another family.
Due to the requirements of IRB-approved protocols, patients without evidence of a hereditary syndrome were not routinely tested for the presence of possible germ-line mutations of relevant disease-causing genes until after 2003. Thus, only 4 of the 26 patients without evidence of a hereditary syndrome were tested for germ-line mutations of relevant disease-causing genes. These 4 patients had no evidence of such mutations. Nevertheless, it remains possible that among the other 22 patients, some may have harboured mutations. The group of 26 patients without evidence of a hereditary syndrome are therefore referred to as having non-syndromic rather than sporadic phaeochromocytoma.

Patients with non-syndromic phaeochromocytoma were divided into two groups with either tumours that produced predominantly noradrenaline (noradrenergic biochemical phenotype) or a combination of adrenaline and noradrenaline (adrenergic biochemical phenotype), as described elsewhere (3, 10). Patients with the noradrenergic tumour phenotype had tumours that contained more than 95\% noradrenaline and less than 5\% adrenaline, whereas patients with the adrenergic phenotype had tumours containing more than $10 \%$ adrenaline and less than $90 \%$ noradrenaline.

\section{Collection of blood and tissue samples}

Blood samples were obtained from patients at the time of diagnostic evaluation before resection of tumours. Samples were taken using an indwelling intravenous catheter inserted into a forearm vein, with patients supine for at least $20 \mathrm{~min}$ before blood collection. Samples of blood were transferred into tubes containing heparin as anticoagulant and immediately placed on ice until centrifuged $\left(4^{\circ} \mathrm{C}\right)$ to separate the plasma. Plasma samples were stored at $-80^{\circ} \mathrm{C}$ until assayed.

Samples of tumour tissue were obtained within $90 \mathrm{~min}$ of surgical removal of phaeochromocytomas. Dimensions of tumours were recorded, with care taken to ensure that measured dimensions represented those of actual tumours or nodules rather than entire resected masses. Small samples (50-400 mg) of tumour tissue were dissected away, placed on dry ice or optimal cutting temperature (OCT) blocks and then stored at $-80{ }^{\circ} \mathrm{C}$. Other samples of tissue were placed in $2.5 \%$

Table 1 Patient data.

\begin{tabular}{|c|c|c|c|c|}
\hline & \multicolumn{2}{|c|}{ Hereditary phaeochromocytoma } & \multicolumn{2}{|c|}{ Non-syndromic phaeochromocytoma* } \\
\hline & MEN 2 & VHL & Adrenergic & Noradrenergic \\
\hline $\mathrm{n}$ & 13 & 18 & 15 & 11 \\
\hline Gender (F/M) & $9 / 4$ & $10 / 8$ & $4 / 11$ & $6 / 5$ \\
\hline Age (mean, range) & $38(17-75)$ & $28(10-50)$ & $57(30-75)+\S$ & $47(22-67) \dagger$ \\
\hline
\end{tabular}

*Patients with non-syndromic phaeochromocytoma are divided into two subgroups with either a noradrenergic (noradrenaline predominant) or adrenergic (mixed adrenaline and noradrenaline) biochemical phenotype as described elsewhere $(3,10)$. $†$ Significantly $(P<0.02)$ higher age than in $\mathrm{VHL}$ patients; $\S$ Significantly $(P<0.01)$ higher age than in MEN 2 patients. 
glutaraldehyde for examination by electron miscroscopy or formalin-fixed for immunohistochemistry.

Samples of normal adrenal tissue for examination of transporter gene expression were procured from three patients undergoing surgery at the NIH for renal cell cancer (requiring removal of both the kidney and adjacent adrenal). Adrenals were transected into sections and small samples of medulla $(5-20 \mathrm{mg})$ were dissected away from surrounding cortex over ice. Paraffin embedded sections of normal human adrenal tissue $(n=4)$ were also purchased from Biocompare Pty Ltd (San Francisco, CA, USA).

\section{Tissue and plasma catecholamines}

Tissue and plasma concentrations of catecholamines (noradrenaline, adrenaline and dopamine) were quantified by liquid chromatography with electrochemical detection (11). Samples of tumour tissue were weighed frozen and homogenized in 5 to 10 volumes of $0.4 \mathrm{M}$ perchloric acid containing $0.5 \mathrm{mM}$ EDTA. Homogenates were centrifuged and supernatants collected for catecholamine determinations. Plasma concentrations of metanephrines (normetanephrine and metanephrine) were determined using a different liquid chromatography procedure after extraction onto solid phase ion exchange columns (12).

\section{Tumour catecholamine release}

Release of catecholamines by tumours was examined based on our previous observations of positive linear relationships of tumour size and total tumour catecholamine content with plasma catecholamines $(4,10)$. Increases of plasma catecholamines above normal in patients with phaeochromocytoma were estimated using our published data on normal plasma concentrations of noradrenaline and adrenaline in a reference population of 285 individuals (13). Subtraction of the mean plasma concentration of noradrenaline
$(1.18 \mathrm{nmol} / \mathrm{l})$ and adrenaline $(0.10 \mathrm{nmol} / \mathrm{l})$ in this reference population from the respective concentrations of noradrenaline and adrenaline in patients with phaeochromocytoma provided estimates of increases in plasma concentrations of catecholamines due to tumours. The combined increases of noradrenaline and adrenaline above normal (nmol/l) were then divided by either tumour masses (g) or total tumour catecholamine contents (mmol) to obtain estimates of tumour catecholamine release as respective functions of tumour size $(\mathrm{nmol} / \mathrm{l}$ per $\mathrm{g}$ of tumour) and catecholamine content (nmol/l per mmol of tumour catecholamine).

Since accurate weights of tumours were difficult to obtain for resected masses containing significant adhering connective tissue, tumour mass was calculated from the more accurate recordings of tumour dimensions. Mean diameters of each tumour were calculated from the cubed roots of rectangular volumes, as described previously (10). Volumes of tumours (V) were estimated using the formula for the volume of a sphere, $V=4 / 3$ $\pi r^{3}$, where $r$, the radius, was derived from estimated mean diameters. Total tumour catecholamine contents were estimated from the product of tissue catecholamine concentrations and tumour mass (estimated from tumour volume, assuming a specific gravity of 1.0).

\section{Quantitative PCR}

RNA was extracted from phaeochromocytoma tumour tissue after homogenization in TRIzol reagent (Invitrogen, Carlsbad, CA, USA) followed by RNeasy Maxi (Qiagen, Valencia, CA, USA) according to the manufacturer's recommendations. Total RNA $(2 \mu \mathrm{g})$ was reversibly transcribed to cDNA using random hexamers. Quantitative PCR (TaqMan PCR), using a 7000 Sequence Detector (Applied Biosystems, Foster City, CA, USA), was used for quantification of mRNA for VMAT 1, VMAT 2 and the noradrenaline transporter as described previously (14). The primers and TaqMan probes were designed from the human noradrenaline

Table 2 Oligonucleotide primers and probes used in PCR.

\begin{tabular}{|c|c|c|}
\hline Primers & Oligonucleotide sequence & Positions $^{a}$ \\
\hline \multicolumn{3}{|l|}{ VMAT 1} \\
\hline Forward & 5'-TGA CAT GGA GTT CAA AGA AGT CAA C & $417-442$ \\
\hline Reverse & $5^{\prime}$-GAG AGG CGA GGG CAT GTG & $493-475$ \\
\hline TaqMan & $5^{\prime}$ (FAM)-CAC CTC GGC CAT GCC GGA AGT T-(TAMRA) & $451-473$ \\
\hline \multicolumn{3}{|c|}{ 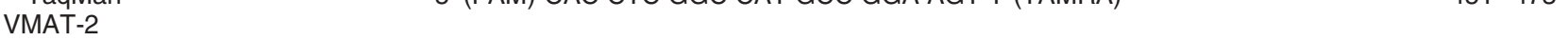 } \\
\hline Forward & 5'-TTC ATC AGA CCG CCA CAC A & $406-425$ \\
\hline Reverse & $5^{\prime}-\mathrm{ACT}$ GGG ACA GTC GGA AGG AA & $470-450$ \\
\hline TaqMan & $5^{\prime}$-(FAM)-CAC ATG GTG ACC AAC GCG TCC G-(TAMRA) & $426-448$ \\
\hline \multicolumn{3}{|c|}{ Noradrenaline transporter } \\
\hline Forward & 5'-GGA AGC CAT CGG AGT TTC CT & $1510-1529$ \\
\hline Reverse & $5^{\prime}$-GAA CTT CCA GCA CAG TCT CCA GTA & $1618-1595$ \\
\hline TaqMan & $5^{\prime}$-(FAM)-CAG GTT CAG CAA CGA CAT CCA GCA & $1546-1571$ \\
\hline
\end{tabular}

${ }^{a}$ The number indicated corresponding to residues within VMAT-1 (Genbank accession no NM003053), VMAT-2 (L23205) or noradrenaline transporter (NM001043) sequence. 
transporter, VMAT 1 and VMAT 2 gene sequences using the Primer Express program from Applied Biosystems (Table 2).

Beta-actin was used as a housekeeping gene (Human $\beta$-actin Pre-Developed TaqMan Assay Reagents, Applied Biosystems) to normalize quantification of noradrenaline transporter, VMAT 1 and VMAT 2 mRNA for differences in the amounts of total RNA added to each cDNA reaction. PCR amplifications of $\beta$-actin and the noradrenaline transporter, VMAT 1 or VMAT 2 were carried out in the same tubes. Reaction tubes contained $20 \mathrm{ng}$ cDNA product as template, $1 \times$ TaqMan Universal PCR Master Mix, $0.9 \mu \mathrm{mol} / \mathrm{l}$ for each of the forward and reverse primers for the noradrenaline transporter, VMAT 1 or VMAT $2,0.2 \mu \mathrm{mol} / \mathrm{l}$ for TaqMan probes for the noradrenaline transporter, VMAT 1 or VMAT 2, and $1 \times$ human $\beta$-actin primers and probe, all to a final volume of $50 \mu \mathrm{l}$ with $\mathrm{H}_{2} \mathrm{O}$. PCR involved 40 cycles at the following temperature parameters: 15 seconds at $95^{\circ} \mathrm{C}, 1 \mathrm{~min}$ at $60^{\circ} \mathrm{C}$. Input RNA amounts were calculated manually using the comparative $\mathrm{Ct}$ method for the target genes and $\beta$-actin.

\section{Western blots}

Western blot analysis of the noradrenaline transporter utilized samples of phaeochromocytoma tissue embedded in OCT blocks, which were sectioned $(8-$ 18 microns, depending on tumour size) and immediately lysed in T-per tissue protein extraction reagent, containing $12 \mathrm{mM}$ bicine, $150 \mathrm{mM}$ sodium chloride (pH 7.6) (Pierce Biotechnology, Rockford, IL, USA), with a protease inhibitor cocktail tablet (Roche Applied Science, Indianapolis, IN, USA). Western blot analyses of VMAT 1 and VMAT 2 utilized samples of frozen phaeochromocytoma tissue (about $20 \mathrm{mg}$ ), which were homogenized in $10 \mathrm{mM}$ potassium phosphate buffer, pH 6.8 containing $1 \mathrm{mM}$ EDTA, $10 \mathrm{mM}$ 3-(3cholamidopropyl) dimethylammonio 1-propane sulphate (CHAPS), $1 \mu \mathrm{g} / \mathrm{ml}$ aprotinin, $10 \mu \mathrm{g} / \mathrm{ml}$ each of leupeptin and pepstatin, and $1 \mathrm{mg} / \mathrm{ml}$ of Pefablock (Roche Applied Science). All tissue homogenates were centrifuged for $10 \mathrm{~min}$ at $10000 \mathrm{~g}\left(4^{\circ} \mathrm{C}\right)$, with supernatants removed and stored at $-80^{\circ} \mathrm{C}$.

Different Western blotting protocols were used for each of the three transporters (Table 3). Tissue proteins with reducing agent were separated by electrophoresis on polyacrylamide gels and transferred onto polyvinylidene fluoride (PVDF) membranes (Millipore, Billerica, MA, USA). Unoccupied protein binding sites were blocked by incubating the membranes in blocking buffers overnight at $4^{\circ} \mathrm{C}$. Membranes were then incubated with primary antibodies at optimized dilutions. Membranes were washed with Tris buffer saline $(50 \mathrm{mM}$ Tris, pH 7.4, 0.9\% NaCl) containing 0.05\% Tween-20 and incubated with secondary antibodies. Target protein bands were visualized using appropriate immunodetection systems.

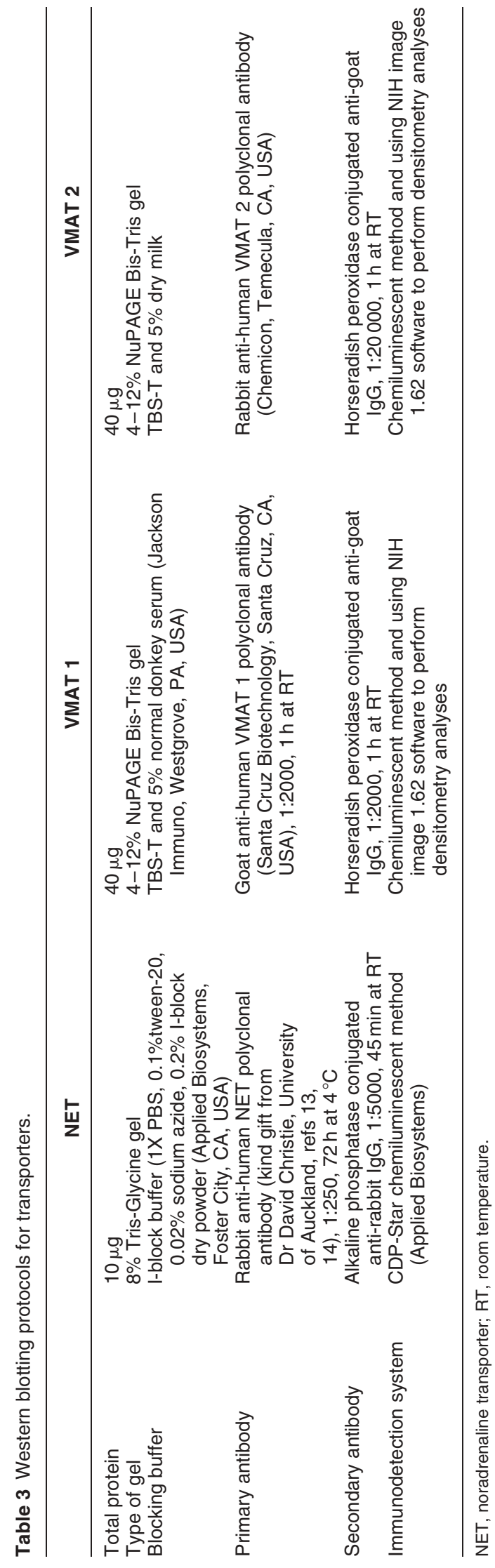




\section{Electron microscopy}

Tissue was double-fixed in PBS-buffered glutaraldehyde $(2.5 \%)$ and osmium tetroxide $(0.5 \%)$, dehydrated, and embedded into Spurr's epoxy resin. Ultrathin sections $(90 \mathrm{~nm})$ were made and double-stained with uranyl acetate and lead citrate, and viewed in a Philips CM10 transmission electron microscope. Vesicular granules were counted blindly in 10 representative tumours from five patients with MEN 2 and five patients with VHL syndrome. Counting was carried out for each tumour on progressive numbers of cells, with the mean count per cell tallied, until a consistent constant mean count was obtained over a final successive series of five cells counted. Counting was done at low magnification where whole cells could be visualized. Therefore, no count was done on partial cells. Since empty vesicles could only be visualized at high magnification, counting was restricted to vesicles containing distinct cores.

\section{Immunohistochemistry}

Formalin fixed sections of normal human adrenals $(n=4)$ and phaeochromocytoma tumour samples from MEN 2 $(n=8)$ and VHL $(n=8)$ patients were deparaffinized and rehydrated by washing twice for $10 \mathrm{~min}$ with xylene, followed by $2 \times 2 \mathrm{~min}$ washes in $100 \%, 95 \%$ and $70 \%(\mathrm{v} / \mathrm{v})$ ethanol. After rinsing with distilled water and immersion in warmed citrate buffer $(0.01 \mathrm{M}, \mathrm{pH}$ 6.0) for $5 \mathrm{~min}$, samples underwent antigen retrieval by immersion in hot citrate buffer $\left(58^{\circ} \mathrm{C}\right)$, followed by heating at $50 \%$ power for $5 \times 5 \mathrm{~min}$ in a $1000 \mathrm{~W}$ microwave oven. Sections were allowed to cool to room temperature before washing for $3 \times 10 \mathrm{~min}$ in $0.1 \mathrm{M}$ phosphate buffer ( $\mathrm{pH} 7.4)$. Sections were then pre-incubated for $1 \mathrm{~h}$ in a blocking solution consisting of $0.1 \mathrm{M}$ PBS containing $10 \mathrm{mM}$ Tris phosphate buffered saline (TPBS), $0.3 \%$ Triton X-100, $0.1 \%(\mathrm{w} / \mathrm{v})$ sodium azide and $10 \%$ normal donkey serum (Jackson Immuno, Westgrove, PA, USA). Primary antibodies for the noradrenaline transporter (affinity purified rabbit anti-noradrenaline transporter antibody; $1: 100,0.125 \mu \mathrm{g} / \mathrm{ml}$ ), as characterized elsewhere $(15,16)$, and for tyrosine hydroxylase (mouse monoclonal anti-tyrosine hydroxylase, 1:500; Diasorin, Saluggia, Italy) were diluted in the blocking solution and slides were incubated for 24 to $48 \mathrm{~h}$ at $4^{\circ} \mathrm{C}$ in a humidified chamber. Following incubation, slides were washed $(3 \times 10 \mathrm{~min}$ in TPBS $)$ and then incubated for $4 \mathrm{~h}$ at room temperature with species-specific secondary antibodies (donkey anti-rabbit Cy3, 1:500; Jackson Immuno; donkey anti-mouse fluorescein isothiocyanate, 1:500). Slides were then washed $3 \times 10 \mathrm{~min}$ in TPBS and mounted in ProLong Antifade (Molecular Probes, Eugene, OR, USA).

Sections were examined using a Zeiss LSM PASCAL 5 equipped with $\mathrm{Ar} / \mathrm{Kr} 488$-514, He/Ne 543 lasers, used to excite $\mathrm{Cy}-3$, FITC. Multipass emissions were collected through the following filters: FITC, bandpass 505-530; Cy-3, bandpass 560-615; using a 63x NeoFluor objective lens, pinhole, detector gain, and laser power were adjusted accordingly to acquire approximately $5 \mu \mathrm{m}$ thick sections with few saturated pixels. Images were acquired with LSM 5 Image Browser software (Zeiss, Thornwood, NY, USA). While overall contrast was adjusted, no other modifications were made.

\section{Statistical analysis}

Statistical methods, performed with Statview (SAS Institute, Inc., Cary, NC, USA), included Student's t-test, the Mann-Whitney test, regression analysis, and for comparisons involving more than two groups, analysis of variance with Sheffe's test as the post-hoc test of choice. Logarithmic transformations were carried out before parametric analyses to correct for non-normally distributed data, as described elsewhere (13). Non-parametric analyses using the Mann-Whitney test were performed as a second check of statistical significance for all comparisons involving two groups. P-values for such comparisons are presented as the minimal level of statistical significance achieved by either test. In the single case where statistical significance (defined as a $P$-value less than 0.05 ) was not reached by both tests, the difference in $P$-values between tests is noted in the text and the legend to the particular figure. Relationships between variables were analysed by regression analysis using both parametric and non-parametric analyses, the latter using Spearman's rank correlation coefficient. Only relationships that were significant by both regression analyses are described, with correlation coefficients and significance levels presented as obtained using parametric analyses.

\section{Results}

\section{Tumour and plasma catecholamines}

Noradrenaline accounted for $98 \%$ of the total catecholamine contents in phaeochromocytomas from VHL patients, whereas in MEN 2 patients, noradrenaline accounted for only $53 \%$ and adrenaline $47 \%$ of total tumour catecholamine contents (Table 4). Combined tissue concentrations of noradrenaline and adrenaline in MEN 2 tumours $(59.8 \pm 11.4 \mu \mathrm{mol} / \mathrm{g})$ were 4 -fold higher $(P<0.001)$ than concentrations in VHL tumours $(15.3 \pm 2.7 \mu \mathrm{mol} / \mathrm{g})$. This difference reflected effects of both 93-fold higher $(P<0.001)$ tissue concentrations of adrenaline and 2 -fold higher $(P<0.04)$ tissue concentrations of noradrenaline in tumours from MEN 2 patients than in those from VHL patients. Consistent with the above pattern and previous observations that increases in plasma normetanephrine and metanephrine accurately reflect tumour contents of noradrenaline and adrenaline (10), plasma concentrations of metanephrine were 18 -fold higher $(P<0.001)$ in 
Table 4 Tumour diameters and catecholamine concentrations, plasma catecholamines and metanephrines and tumour catecholamine release in hereditary phaeochromocytomas.

\begin{tabular}{|c|c|c|}
\hline & $\begin{array}{c}\text { VHL } \\
(n=18)\end{array}$ & $\begin{array}{c}\text { MEN } 2 \\
(n=13)\end{array}$ \\
\hline Mean tumour diameter $(\mathrm{cm})$ & $2.6 \pm 0.2$ & $4.3 \pm 0.6^{*}$ \\
\hline \multicolumn{3}{|l|}{ Tumour catecholamines } \\
\hline Noradrenaline $(\mu \mathrm{mol} / \mathrm{g})$ & $15.0 \pm 2.7$ & $32.0 \pm 8.1^{*}$ \\
\hline Adrenaline $(\mu \mathrm{mol} / \mathrm{g})$ & $0.3 \pm 0.1$ & $27.8 \pm 6.9^{* \star \star}$ \\
\hline \multicolumn{3}{|l|}{ Plasma catecholamines } \\
\hline Noradrenaline (nmol/l) & $5.8 \pm 1.1$ & $4.8 \pm 1.3$ \\
\hline Adrenaline $(\mathrm{nmol} / \mathrm{l})$ & $0.1 \pm 0.0$ & $1.0 \pm 0.3^{* * *}$ \\
\hline \multicolumn{3}{|l|}{ Plasma metanephrines } \\
\hline Normetanephrine (nmol/l) & $2.4 \pm 0.4$ & $5.6 \pm 1.9$ \\
\hline Metanephrine $(\mathrm{nmol} / \mathrm{l})$ & $0.2 \pm 0.0$ & $3.5 \pm 1.7^{* * *}$ \\
\hline \multicolumn{3}{|l|}{ Tumour catecholamine release } \\
\hline (nmol/l per mmol tumour catecholamine) & $76 \pm 21$ & $12 \pm 9 * \star \star$ \\
\hline
\end{tabular}

All values are means \pm S.E.M. ${ }^{*} P<0.05,{ }^{* *} P<0.01,{ }^{* * *} P<0.001$.

MEN 2 patients than in VHL patients, while normetanephrine concentrations were 2.3-fold higher in MEN 2 patients than VHL patients, though the latter difference did not reach significance.

Plasma concentrations of adrenaline were 9-fold higher $(P<0.001)$ in MEN 2 patients than in VHL patients, whereas plasma concentrations of noradrenaline were not significantly different (Table 4). Although the combined sum of plasma concentrations of noradrenaline and adrenaline did not differ between patients with VHL syndrome and MEN 2 (5.9 \pm 1.1 versus $5.8 \pm 1.6 \mathrm{nmol} / \mathrm{l})$, significant differences in catecholamine release emerged when differences in tumour size and tumour catecholamine content were considered. When corrected for differences in tumour mass, increases in plasma catecholamines in VHL patients were 2.5 -fold higher $(P<0.03)$ than in MEN 2 patients. When further corrected for differences in total tumour catecholamine content, increases in plasma catecholamines in VHL patients were 6.3-fold higher than in MEN 2 patients.

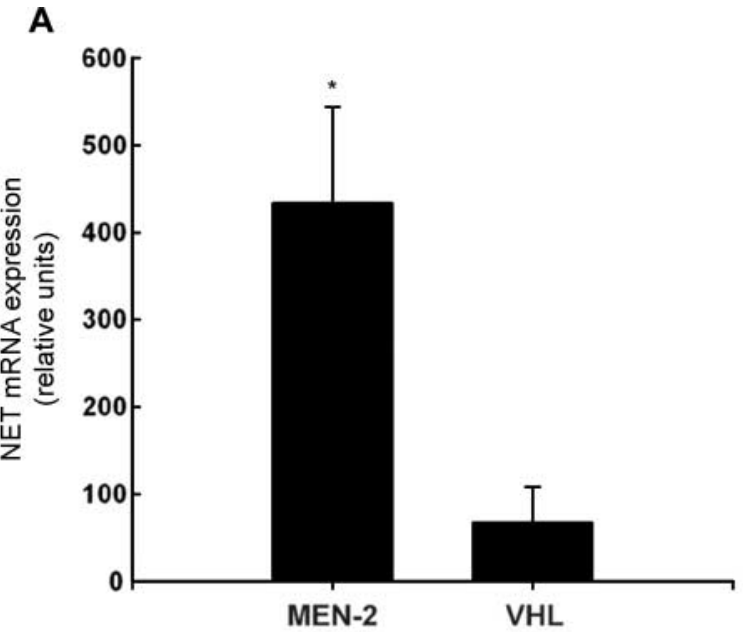

B

MEN 2 VHL

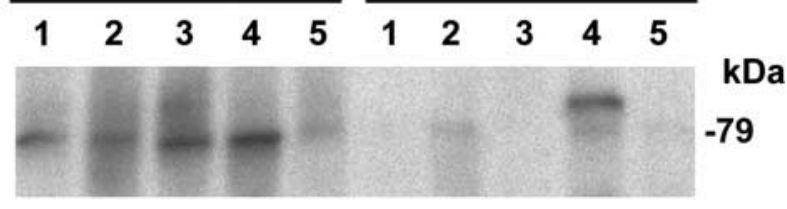

Figure 1 Expression of noradrenaline transporter mRNA (A) and protein (B) in phaeochromocytomas from patients with MEN 2 and VHL syndrome. Levels of noradrenaline transporter mRNA in tumours from ten patients with VHL syndrome and ten patients with MEN 2 (mean \pm S.E.M.), were determined by quantitative PCR, with expression shown relative to that of $\beta$-actin mRNA, as described in the Materials and methods section. Noradrenaline transporter protein in the Western blot is shown by the $79 \mathrm{kDa}$ bands in five tumours from both groups. ** Significantly $(P<0.002)$ higher expression in MEN 2 than VHL tumours.

Similar differences to the above in predominantly noradrenaline-producing (noradrenergic) VHL tumours and adrenaline-producing (adrenergic) MEN 2 tumours were also observed in patients with noradrenergic and adrenergic non-syndromic phaeochromocytomas

Table 5 Tumour diameters and catecholamine concentrations, plasma catecholamines and metanephrines and tumour catecholamine release in non-syndromic phaeochromocytomas.

\begin{tabular}{|c|c|c|}
\hline & Noradrenergic $(n=11)$ & Adrenergic $(n=15)$ \\
\hline Mean tumour diameter $(\mathrm{cm})$ & $3.6 \pm 0.4$ & $5.0 \pm 0.6$ \\
\hline \multicolumn{3}{|l|}{ Tumour catecholamines } \\
\hline Noradrenaline $(\mu \mathrm{mol} / \mathrm{g})$ & $11.5 \pm 4.5$ & $20.0 \pm 7.5$ \\
\hline Adrenaine $(\mu \mathrm{mol} / \mathrm{g})$ & $0.1 \pm 0.0$ & $12.1 \pm 2.9^{\star \star \star}$ \\
\hline \multicolumn{3}{|l|}{ Plasma catecholamines } \\
\hline Noradrenaline (nmol/l) & $25.3 \pm 7.6$ & $9.1 \pm 2.5^{\star \star}$ \\
\hline Adrenaline $(\mathrm{nmol} / \mathrm{l})$ & $0.4 \pm 0.1$ & $2.76 \pm 0.9^{* *}$ \\
\hline \multicolumn{3}{|l|}{ Plasma metanephrines } \\
\hline Normetanephrine (nmol/l) & $10.8 \pm 2.9$ & $8.5 \pm 2.9$ \\
\hline Metanephrine $(\mathrm{nmol} / \mathrm{l})$ & $0.6 \pm 0.2$ & $4.89 \pm 1.2^{\star \star \star}$ \\
\hline \multicolumn{3}{|l|}{ Tumour catecholamine release } \\
\hline (nmol/l per g tumour tissue) & $1.48 \pm 0.49$ & $0.32 \pm 0.08^{\star *}$ \\
\hline (nmol/l per mmol tumour catecholamine) & $200 \pm 88$ & $34 \pm 11^{*}$ \\
\hline
\end{tabular}

All values are means \pm S.E.M. ${ }^{*} P<0.05,{ }^{* \star} P<0.01,{ }^{* \star *} P<0.001$. 


\section{VMAT 1}
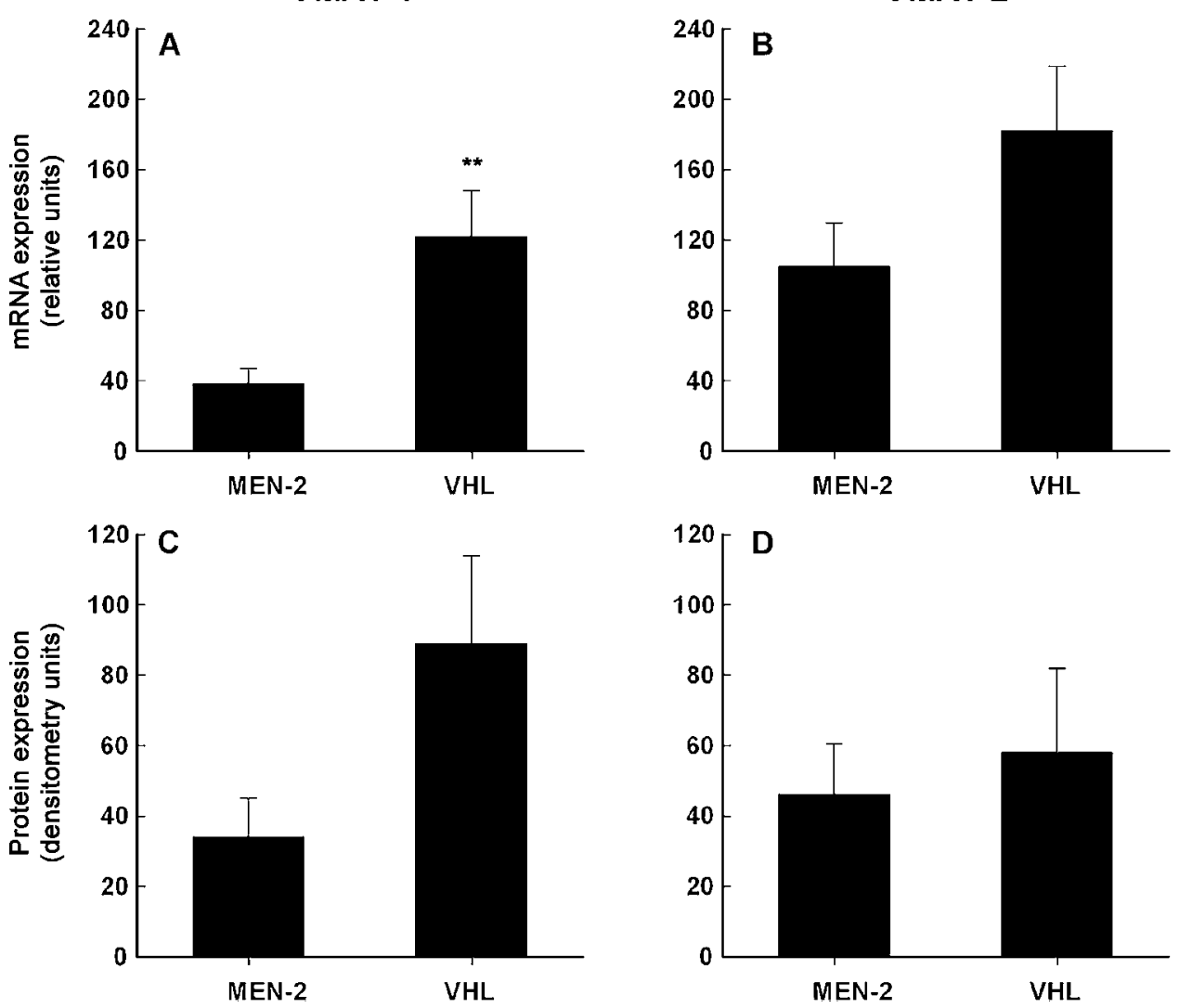

Figure 2 Expression of VMAT 1 and VMAT 2 mRNA (A \& B) and protein (C \& D) in phaeochromocytomas from patients with MEN 2 and VHL syndrome (mean \pm S.E.M.). Levels of expression of mRNA were determined by quantitative PCR in tumours from 11 MEN 2 and $14 \mathrm{VHL}$ patients, with expression shown relative to that of $\beta$-actin mRNA, as described in the Materials and methods section. Expression of VMAT 1 and VMAT 2 protein in Western blots was determined by densitometry, using NIH image 1.62 software, in tumours from 11 MEN 2 and 12 VHL patients. **Significantly $(P<0.007)$ higher expression in VHL than MEN 2 tumours.

(Table 5). In particular, combined tissue concentrations of noradrenaline and adrenaline in adrenergic non-syndromic tumours $(32.1 \pm 10.4 \mu \mathrm{mol} / \mathrm{gm})$ were 2.8 -fold higher $(P<0.04)$ than in noradrenergic non-syndromic tumours $(11.6 \pm 4.5 \mu \mathrm{mol} / \mathrm{g})$. Furthermore, increases in plasma catecholamines as a function of tumour mass were 4.6-fold higher $(P<0.007)$ in patients with noradrenergic than adrenergic tumours. When further corrected for differences in total tumour catecholamine content, increases in plasma catecholamines in patients with noradrenergic non-syndromic tumours were 5.9-fold higher $(P<0.02)$ than in patients with adrenergic tumours.

\section{Expression of the noradrenaline transporter}

Quantitative PCR indicated a 6-fold higher $(P<0.002)$ amount of noradrenaline transporter mRNA in phaeochromocytoma tumour tissue from MEN 2 patients than from VHL patients (Fig. 1A). Consistent with this, Western blot analysis indicated consistently detectable noradrenaline transporter protein in phaeochromocytoma tissue from MEN 2 patients, compared with no or only faintly detectable noradrenaline transporter protein in tumours from VHL patients (Fig. 1B).

Expression of the noradrenaline transporter, measured by quantitative PCR, tended to be higher in non-syndromic adrenergic tumours $(520 \pm 170$ relative units, $n=9)$ than noradrenergic tumours $(292 \pm 170$ relative units, $n=8$ ), but this difference did not reach statistical significance. Thus, in contrast to the large difference in noradrenaline transporter expression in hereditary phaeochromocytomas, any difference in tumours from patients with non-syndromic phaeochromocytoma was relatively modest.

Expression of the noradrenaline transporter in the three samples of normal adrenal medulla $(47 \pm 8$ relative units) was relatively low compared with expression in phaeochromocytomas.

\section{Expression of vesicular monoamine transporters}

In contrast to expression of the noradrenaline transporter, expression of VMAT 1 mRNA was $69 \%$ lower $(P<0.007)$ in phaeochromocytomas from MEN 2 

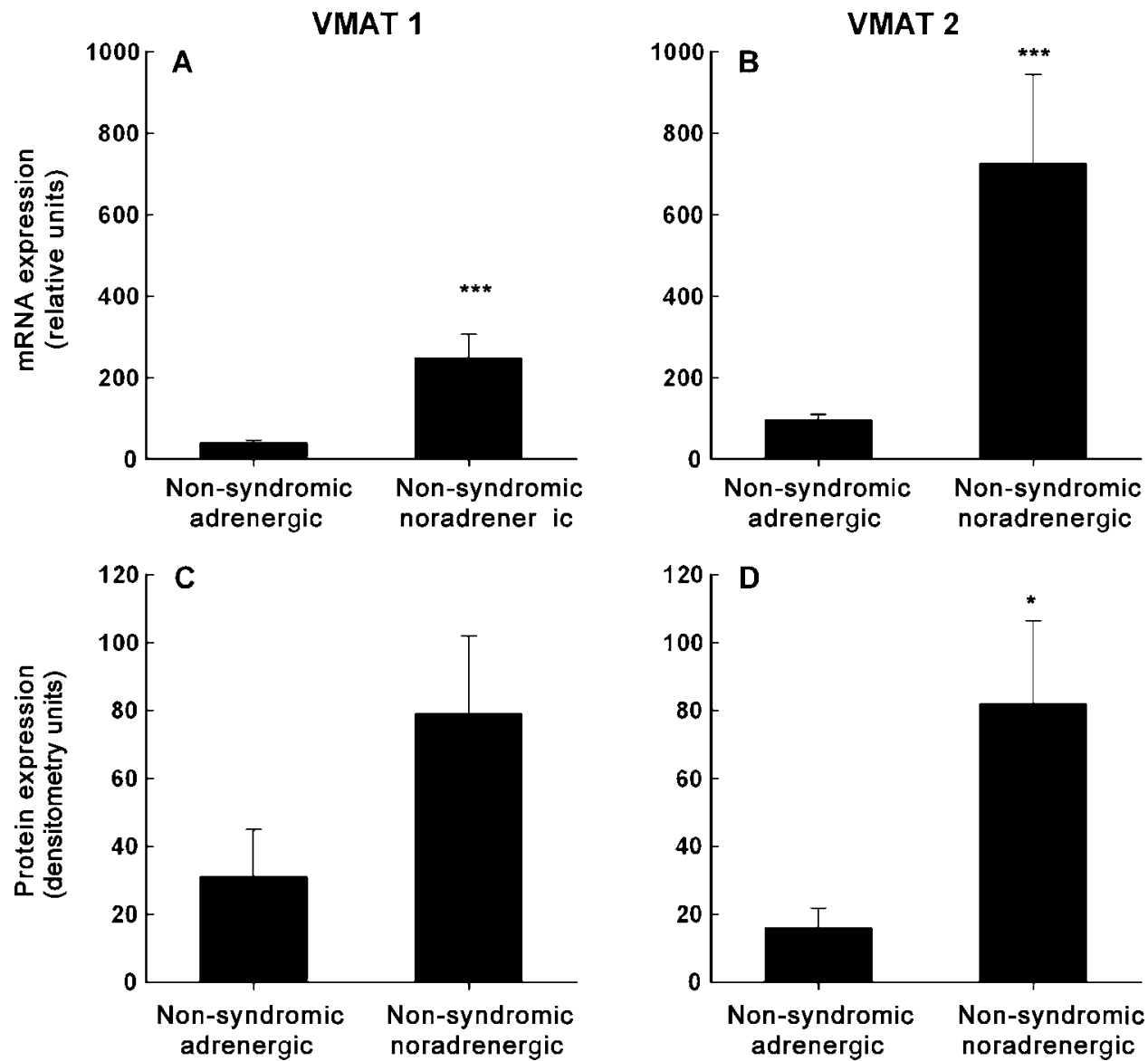

Figure 3 Expression of VMAT 1 and VMAT 2 mRNA (A \& B) and protein (C \& D) in tumours from patients with non-syndromic phaeochromocytoma (mean \pm S.E.M.). Levels of expression of $\mathrm{mRNA}$ were determined by quantitative PCR in phaeochromocytomas from 15 patients with adrenergic tumours and 11 patients with noradrenergic tumours. Expression of VMAT 1 and VMAT 2 mRNA is shown relative to that of $\beta$-actin mRNA, as described in the Methods section. Expression of VMAT 1 and VMAT 2 protein in Western blots was determined by densitometry using NIH image 1.62 software in phaeochromocytomas from 13 patients with adrenergic tumours and eight patients with noradrenergic tumours. *Significantly $(P<0.05)$ higher expression in non-syndromic noradrenergic than adrenergic tumours. ${ }^{* *}$ Significantly $(P<0.001)$ higher expression in non-syndromic noradrenergic than adrenergic tumours. Note: The difference in VMAT 1 protein expression, although significant by parametric analysis $(P=0.038)$, failed to reach significance by non-parametric analysis $(P=0.070)$

patients than from VHL patients (Fig. 2A). Similarly, expression of VMAT 1 protein was $62 \%$ lower in MEN 2 than VHL tumours (Fig. 2C), but this difference did not reach significance. Expression of VMAT 2 mRNA and protein also tended to be lower in MEN 2 than VHL tumours, but these differences also did not reach significance (Fig. 2B \& D).

Following a similar but more dramatic pattern to the differences in hereditary noradrenergic and adrenergic tumours, levels of expression of VMAT 1 and VMAT 2 were lower in adrenergic than noradrenergic non-syndromic tumours (Fig. 3). Quantitative PCR indicated $84 \%$ lower $(P<0.001)$ levels of expression of VMAT 1 mRNA and $87 \%$ lower $(P<0.001)$ levels of expression of VMAT 2 mRNA in non-syndromic adrenergic tumours than noradrenergic tumours (Fig. 3A \& B). Similarly, VMAT 1 and VMAT 2 protein were respectively expressed at $61 \%$ and $80 \%$ lower levels in non-syndromic adrenergic tumours than noradrenergic tumours (Fig. 3C \& D). These latter two differences, however, were only significant $(P<0.05)$ for VMAT 2. The difference in VMAT 1 protein expression, although significant by parametric analysis $(P=0.038)$, failed to reach significance by non-parametric analysis $(P=0.070)$.

Expression of VMAT 1 mRNA in the three samples of normal human adrenal medulla (63 \pm 38 relative units) was intermediate between levels of expression in noradrenergic and adrenergic hereditary or non-syndromic phaeochromocytomas. Expression of VMAT 2 mRNA in the three samples (186 \pm 107 relative units) was similar to that in hereditary and non-syndromic adrenergic tumours, but lower than in non-syndromic noradrenergic tumours.

There were significant positive relationships between expression of VMAT 1 mRNA and protein $(r=0.41$, 

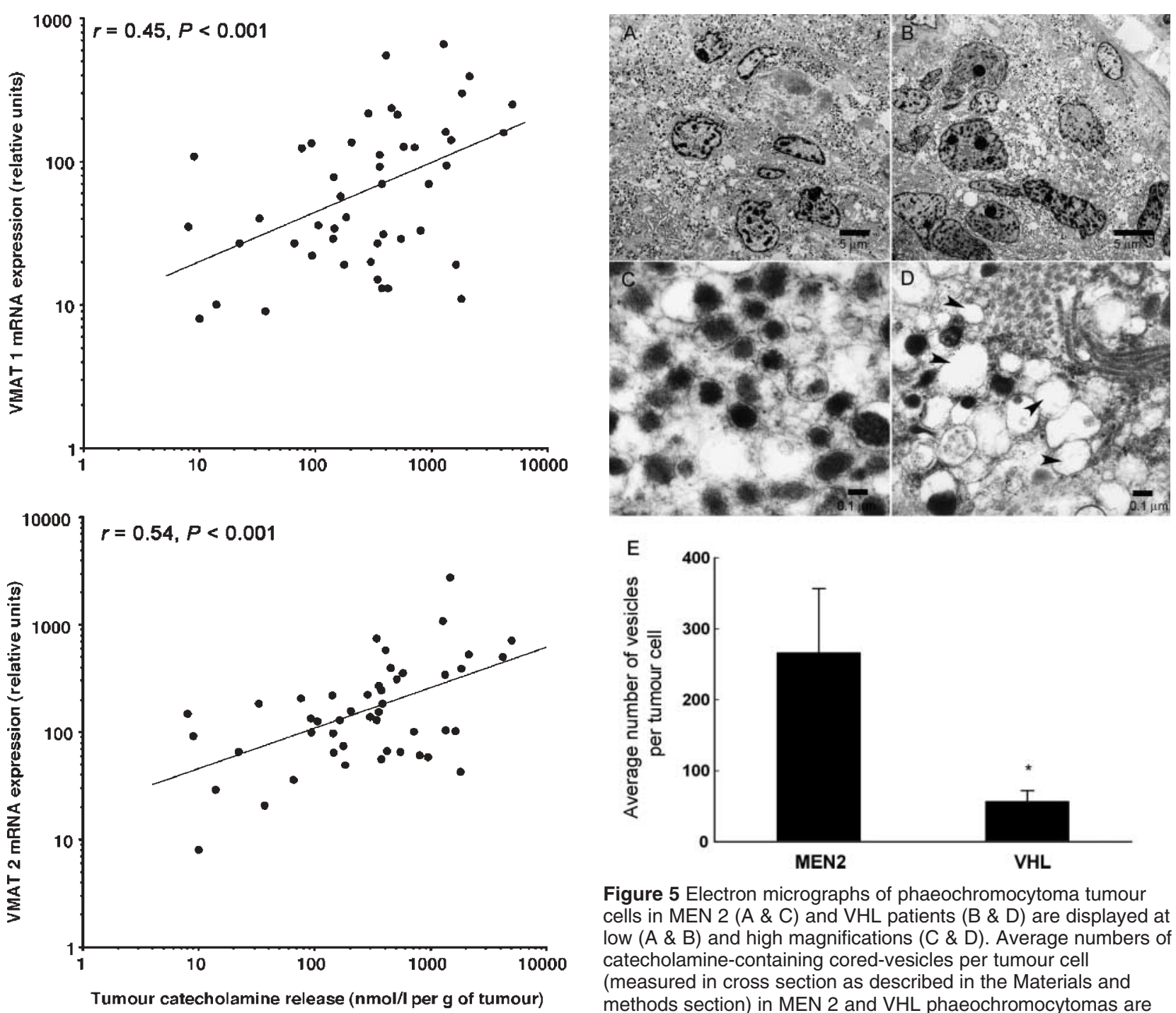

Figure 5 Electron micrographs of phaeochromocytoma tumour cells in MEN 2 (A \& C) and VHL patients (B \& D) are displayed at low $(A \& B)$ and high magnifications $(C \& D)$. Average numbers of catecholamine-containing cored-vesicles per tumour cell (measured in cross section as described in the Materials and methods section) in MEN 2 and VHL phaeochromocytomas are shown in panel E. At low magnification (bar $=5 \mu \mathrm{m}$ ), the distribution of cored-vesicles on electron micrographs is sparser in VHL tumour cells than in MEN 2 tumour cells (panels A \& B). At high magnification (bar $=0.1 \mu \mathrm{m}$ ), numerous empty vesicles were apparent in VHL tumour cells (see arrow heads), but not MEN 2 tumour cells (panels $C \& D$ ). *Significantly $(P=0.012)$ lower numbers of vesicles in VHL than MEN 2 tumours.

$P=0.006)$, VMAT 2 mRNA and protein $(r=0.30$, $P=0.047)$, VMAT 1 and VMAT 2 mRNA $(r=0.68$, $P<0.0001)$ and VMAT 1 and VMAT 2 protein $(r=0.64, P<0.001)$ for the combined data from all four groups of phaeochromocytomas. Significant positive relationships were also found between expression of mRNA for VMAT $1 \quad(r=0.45, \quad P=0.002)$ or VMAT $2(r=0.54, \quad P<0.001)$ and increases in plasma catecholamines as a function of tumour size (Fig. 4). Relationships with increases in plasma catecholamines as a function of total tumour catecholamine contents were weaker, but also positively related to expression of mRNA for VMAT $1(r=0.35$, $P=0.019)$ and VMAT $2(r=0.48, P<0.001)$.

\section{Electron microscopy}

Electron microscopy revealed different ultrastructural morphologies of phaeochromocytoma tumour cells from VHL and MEN 2 patients (Fig. 5). MEN 2 tumour cells were filled with both noradrenaline and adrenaline granules, whereas VHL tumour cells contained fewer predominantly noradrenaline granules and many empty vesicles. Empty vesicles were not restricted to the regional vicinity of the cell membrane, but were scattered throughout the cytoplasm as a characteristic of VHL tumour cells. Empty vesicles were not observed in MEN 2 tumours. Numbers of catecholamine containing vesicles (vesicles with cores) 


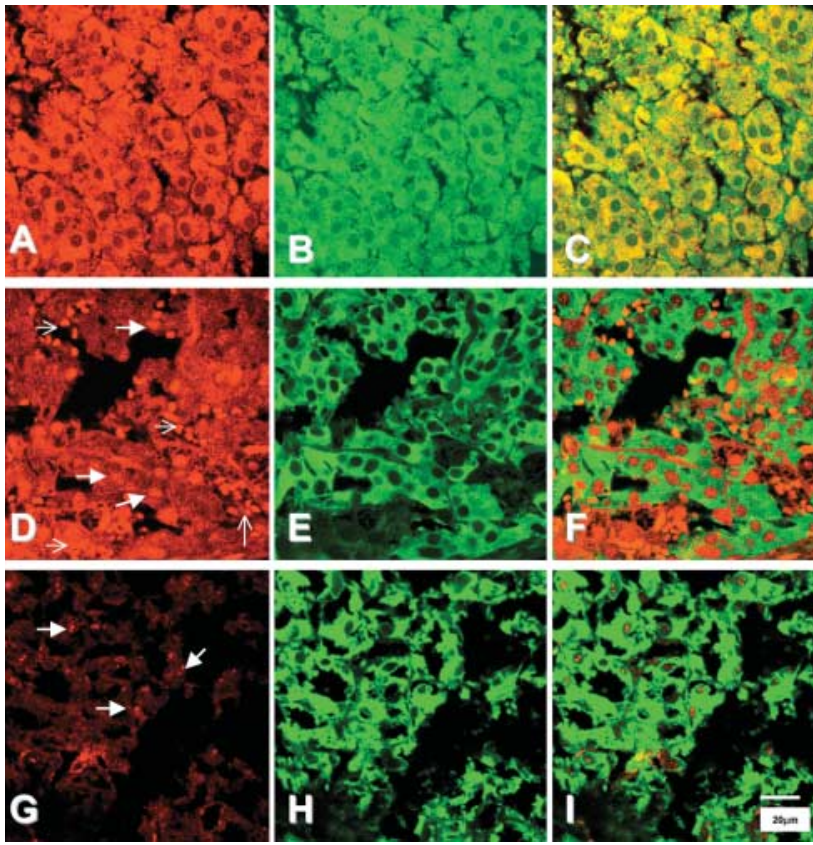

Figure 6 Immunohistochemical staining of the noradrenaline transporter (red, A, D, G), and tyrosine hydroxylase (TH) (green, $B, E, H$ ) in representative samples of the normal human adrenal medulla $(A-C)$ and in phaeochromocytomas from patients with MEN 2 (D-F) and VHL syndrome $(G-I)$. Staining of the transporter in the normal adrenal was present within the cytoplasm, and colocalized with staining for TH (C). In contrast, the pattern of staining for the noradrenaline transporter in tumour samples, of both MEN2 and VHL patients, was highly variable, and did not always appear to colocalize with TH. Thick arrows indicate granular staining for the noradrenaline transporter, thin arrows indicate red blood cells.

were $79 \%$ lower $(P=0.012)$ in VHL tumours than in MEN 2 tumours.

\section{Immunohistochemistry}

Immunohistochemistry indicated expression of the noradrenaline transporter in normal human adrenal medulla and phaeochromocytomas from both MEN 2 and VHL patients (Fig. 6). The noradrenaline transporter was consistently expressed and colocalized with tyrosine hydroxylase in the cytoplasm of chromaffin cells in all normal human adrenal samples. Staining of the noradrenaline transporter was also observed in the cytoplasm of phaeochromocytoma tumour cells of both MEN 2 and VHL patients, but appeared more variable than in normal human adrenal medulla.

\section{Discussion}

This study extends previous observations about differences in catecholamine biosynthetic enzymes among hereditary forms of phaeochromocytoma to other key determinants of catecholamine system function - the transporters responsible for inactivation and storage of catecholamines via cellular uptake and vesicular translocation.

Phaeochromocytomas in the setting of MEN 2, which synthesize substantial amounts of adrenaline, expressed more of the noradrenaline transporter than did tumours in the setting of VHL, which produce negligible adrenaline. In contrast, phaeochromocytomas in VHL patients expressed more VMAT 1 than did those in MEN 2 patients. This was despite lower tissue catecholamine concentrations and numbers of catecholaminecontaining secretory granules in tumours from VHL than from MEN 2 patients. Similar patterns to the above were observed in predominantly noradrenaline-producing (noradrenergic) vs adrenaline-producing (adrenergic) tumours in patients with non-syndromic phaeochromocytoma. However, differences in expression of the noradrenaline transporter were less pronounced, while differences in expression of VMAT 1 and VMAT 2 were more pronounced in non-syndromic than hereditary noradrenergic and adrenergic tumours.

The finding of greater noradrenaline transporter expression in adrenergic MEN 2 tumours than in noradrenergic VHL tumours agrees with other observations that expression of the noradrenaline transporter in rat adrenal chromaffin cells is confined to those cells that express PNMT, the enzyme that converts noradrenaline to adrenaline (9). Together, these findings are also consistent with those of Kobayashi and colleagues (17), who injected mice with tritium-labelled catecholamines and using autoradiography found larger amounts of radioactivity in adrenaline-containing compared with noradrenaline-containing adrenal medullary chromaffin cells. Similarly, the finding of higher expression of VMAT 2 in non-syndromic noradrenergic than adrenergic tumours, is consistent with other findings that VMAT 2 is expressed in noradrenaline-containing, but not adrenaline-containing chromaffin granules of bovine adrenal medulla (7).

There are marked species variations in proportions of adrenaline and noradrenaline containing chromaffin cells (18). In the human adrenal medulla, virtually all chromaffin cells express PNMT. It is therefore unclear how findings of different populations of noradrenaline and adrenaline cells in various animal species relate to development of different catecholamine-producing phaeochromocytomas in humans. Possibly there may exist in the human adrenal medulla a small proportion of noradrenaline cells from which distinctly noradrenaline-producing tumours in VHL patients develop. Alternatively as suggested elsewhere (19), predominant production of noradrenaline in phaeochromocytomas may reflect dedifferentiation, with loss of expression of PNMT and other aspects of the adrenaline phenotype, such as the noradrenaline transporter, occurring more profoundly in hereditary than in sporadic tumours. 
MEN-2

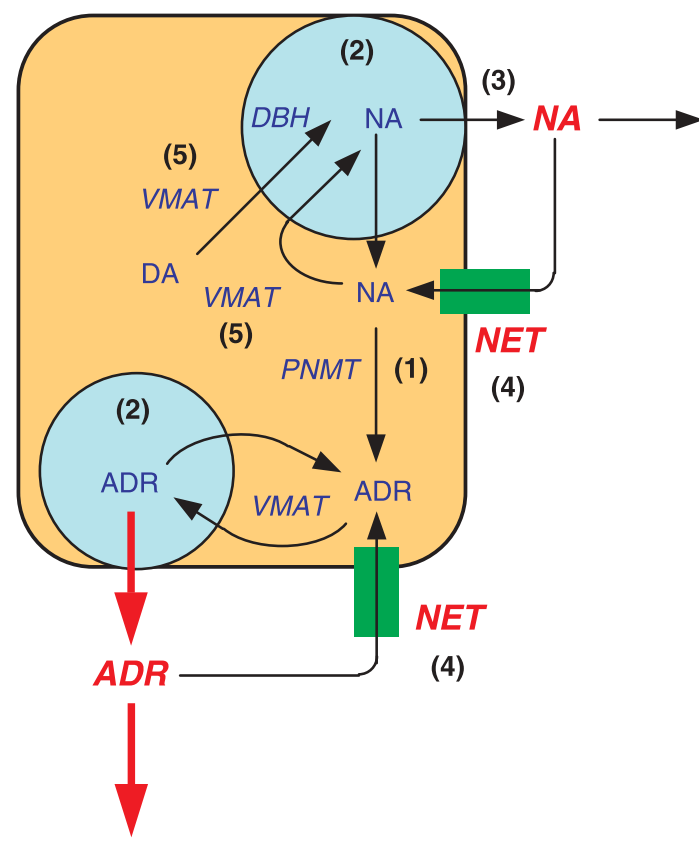

VHL

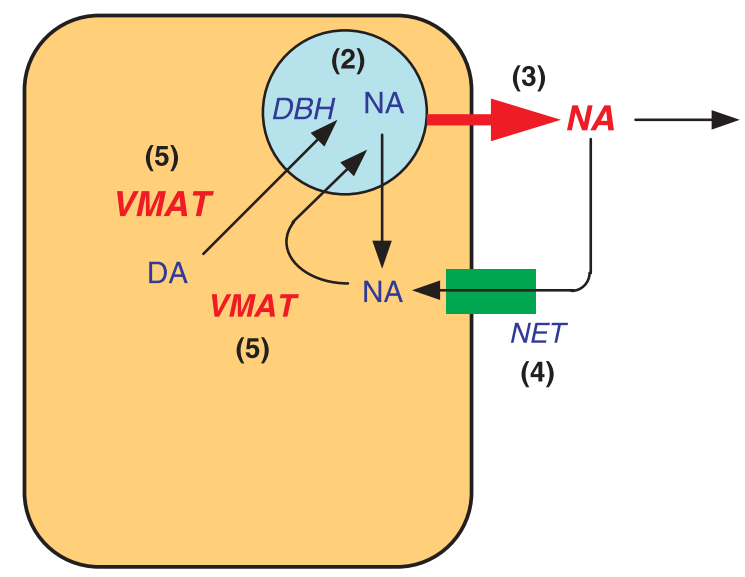

Figure 7 Summary of five differences in the catecholamine phenotypes of MEN 2 and VHL phaeochromocytomas. (1) PNMT is expressed and adrenaline is produced in MEN 2 tumours, but not in VHL tumours; (2) catecholamine contents are lower and numbers of catecholamine-containing cored-vesicles are fewer in VHL tumour cells than in MEN 2 tumour cells; (3) VHL tumours release greater amounts of catecholamines than MEN 2 tumours; (4) expression of the noradrenaline transporter is greater in MEN 2 tumours than in VHL tumours; and (5) Expression of VMAT 1 is greater in VHL tumours than in MEN 2 tumours. DA, dopamine; NA, noradrenaline; ADR, adrenaline; NET, noradrenaline transporter; $\mathrm{DBH}$, dopamine beta hydroxylax.

Since the noradrenaline transporter mediates the cellular uptake of radioiodinated metaiodobenzylguanidine (MIBG) (20), greater noradrenaline transporter expression in phaeochromocytomas from MEN 2 than VHL patients might be expected to make the imaging agent more suitable for localization of tumours in the former than in the latter syndrome. However, tumour visualisation with MIBG also depends importantly on translocation of the agent into catecholamine storage granules (21). Inhibition of VMAT 1 and VMAT 2, the transporters responsible for translocation of catecholamines into vesicles, reduces uptake and retention of MIBG by neuroendocrine tumour cells more consistently than does inhibition of the noradrenaline transporter (22). Thus, the greater expression of VMAT 1 in phaeochromocytomas from VHL than MEN 2 patients might counter the influence of the difference in noradrenaline transporter expression on tumour visualisation by MIBG.

Any functional significance of differences in noradrenaline transporter expression may also be influenced by differences in the subcellular distribution of transporter protein. The present findings of predominantly cytoplasmic rather than cell surface expression of the noradrenaline transporter in hereditary phaeochromocytoma tumour cells is consistent with other observations in rat and human adrenal medullary chromaffin cells and tumour cells in patients with non-syndromic phaeochromocytoma $(9,15,23,24)$. Regulated trafficking of the noradrenaline transporter from the cytoplasm to the cell surface appears to be an important mechanism regulating transporter function (25). Improved tumour visualisation and targeted radiotherapy of malignancies with MIBG by procedures designed to increase expression of the transporter (26, 27) may therefore benefit by additional consideration of the mechanisms regulating functional expression of the transporter at the cell surface.

Greater expression of VMAT 1 in tumours from VHL patients than from MEN 2 patients was associated with lower tumour tissue contents of catecholamines, lower numbers of catecholamine-containing chromaffin granules, and higher numbers of empty vesicles. These differences might reflect the more active release of catecholamines in predominantly noradrenalinethan adrenaline-producing tumours observed elsewhere $(4,10)$, and verified here by the larger increases in plasma catecholamines as functions of tumour size and catecholamine content in noradrenergic than adrenergic hereditary and non-syndromic phaeochromocytomas. Increased expression of VMAT 1 in VHL compared with MEN 2 tumours and of both VMAT 1 and VMAT 2 in non-syndromic noradrenergic than adrenergic tumours might be expected to facilitate 
refilling of the depleted storage granules, a compensatory response to the more rapid turnover of catecholamine stores in predominantly noradrenaline- than adrenaline-producing tumours. This possibility is supported here by the findings of positive relationships between indices of tumour catecholamine release and expression of VMAT 1 and VMAT 2.

The diagram in Fig. 7 summarizes five differences in catecholamine system function in phaeochromocytomas from MEN 2 and in VHL patients: (1) MEN 2 tumours produce adrenaline, whereas VHL tumours do not; (2) VHL tumours have lower numbers of catecholamine-containing vesicles and smaller tissue catecholamine stores than MEN 2 tumours; (3) VHL tumours release more catecholamines than MEN 2 tumours; (4) VHL tumours have less noradrenaline transporter expression; and (5) VHL tumours express more VMAT 1 than MEN 2 tumours.

In conclusion, the divergent expression profiles of catecholamine transporters in phaeochromocytomas from MEN 2 and VHL patients provide further evidence of distinct genotypic differences contributing to the distinctive clinical catecholaminergic phenotypes in these two hereditary phaeochromocytoma syndromes.

\section{Acknowledgements}

We gratefully acknowledge the gift of rabbit antibody to the noradrenaline transporter from Drs David L Christie (Auckland University, New Zealand) and Jacqueline Phillips (Murdoch University, Perth, Western Australia). We also thank Dr Massimo Mannelli (University of Florence, Florence, Italy) for assistance with patients and data collection. This research was supported by the Intramoral Research Program on NIM, National Institute of Neurological Disorders and Stroke, National Cancer Institute, National Institute of Child Health and Human Development and National Human Genome Research Institute.

\section{References}

1 Neumann HP, Bausch B, McWhinney SR, Bender BU, Gimm O, Franke G, Schipper J, Klisch J, Altehoefer C, Zerres K, Januszewicz A, Eng C, Smith WM, Munk R, Manz T, Glaesker S, Apel TW, Treier M, Reineke M, Walz MK, Hoang-Vu C, Brauckhoff M, Klein-Franke A, Klose P, Schmidt H, MaierWoelfle M, Peczkowska M \& Szmigielski C. Germ-line mutations in nonsyndromic pheochromocytoma. New England Journal of Medicine 2002346 1459-1466.

2 Bryant J, Farmer J, Kessler LJ, Townsend RR \& Nathanson KL. Pheochromocytoma: the expanding genetic differential diagnosis. Journal of the National Cancer Institute 200395 1196-1204.

3 Eisenhofer G, Huynh TT, Pacak K, Brouwers FM, Walther MM, Linehan WM, Munson PJ, Mannelli M, Goldstein DS \& Elkahloun AG. Distinct gene expression profiles in norepinephrine-and epinephrine-producing hereditary and sporadic pheochromocytomas: activation of hypoxia-driven angiogenic pathways in von Hippel-Lindau syndrome. Endocrine-Related Cancer $200411897-911$.
4 Eisenhofer G, Walther MM, Huynh TT, Li ST, Bornstein SR, Vortmeyer A, Mannelli M, Goldstein DS, Linehan WM, Lenders JW \& Pacak K. Pheochromocytomas in von HippelLindau syndrome and multiple endocrine neoplasia type 2 display distinct biochemical and clinical phenotypes. Journal of Clinical Endocrinology and Metabolism 200186 1999-2008.

5 Eisenhofer G, Lenders JW, Linehan WM, Walther MM, Goldstein DS \& Keiser HR. Plasma normetanephrine and metanephrine for detecting pheochromocytoma in von Hippel-Lindau disease and multiple endocrine neoplasia type 2. New England Journal of Medicine 1999340 1872-1879.

6 Huynh TT, Pacak K, Brouwers F, Walther MM, Mannelli M, Elkahloun AG, Goldstein DS \& Eisenhofer G. Differences in storage and release of catecholamines in pheochromocytomas in multiple endocrine neoplasia type 2 and von Hippel-Lindau syndrome (abstract). Journal of Internal Medicine 2004255728.

7 Weiss C, Cahill AL, Laslop A, Fischer-Colbrie R, Perlman RL \& Winkler H. Differences in the composition of chromaffin granules in adrenaline and noradrenaline containing cells of bovine adrenal medulla. Neuroscience Letters 1996211 29-32.

8 Erickson JD, Schafer MK, Bonner TI, Eiden LE \& Weihe E. Distinct pharmacological properties and distribution in neurons and endocrine cells of two isoforms of the human vesicular monoamine transporter. PNAS 199693 5166-5171.

9 Phillips JK, Dubey R, Sesiashvilvi E, Takeda M, Christie DL \& Lipski J. Differential expression of the noradrenaline transporter in adrenergic chromaffin cells, ganglion cells and nerve fibres of the rat adrenal medulla. Journal of Chemical Neuroanatomy 2001 21 95-104.

10 Eisenhofer G, Lenders JW, Goldstein DS, Mannelli M, Csako G, Walther MM, Brouwers FM \& Pacak K. Pheochromocytoma catecholamine phenotypes and prediction of tumor size and location by use of plasma free metanephrines. Clinical Chemistry $2005 \mathbf{5 1}$ $735-744$.

11 Eisenhofer G, Goldstein DS, Stull R, Keiser HR, Sunderland T, Murphy DL \& Kopin IJ. Simultaneous liquid-chromatographic determination of 3,4-dihydroxyphenylglycol, catecholamines, and 3,4-dihydroxyphenylalanine in plasma, and their responses to inhibition of monoamine oxidase. Clinical Chemistry 198632 2030-2033.

12 Lenders JW, Eisenhofer G, Armando I, Keiser HR, Goldstein DS \& Kopin IJ. Determination of metanephrines in plasma by liquid chromatography with electrochemical detection. Clinical Chemistry 199339 97-103.

13 Eisenhofer G, Lenders JW \& Pacak K. Biochemical diagnosis of pheochromocytoma. Frontiers of Hormone Research 200431 76-106.

14 Heid CA, Stevens J, Livak KJ \& Williams PM. Real time quantitative PCR. Genome Research 19966 986-994.

15 Kippenberger AG, Palmer DJ, Comer AM, Lipski J, Burton LD \& Christie DL. Localization of the noradrenaline transporter in rat adrenal medulla and PC12 cells: Evidence for its association with secretory granules in PC12 cells. Journal of Neurochemistry 199973 1024-1032.

16 Burton LD, Kippenberger AG, Lingen B, Bruss M, Bonisch H \& Christie DL. A variant of the bovine noradrenaline transporter reveals the importance of the C-terminal region for correct targeting to the membrane and functional expression. Biochemical Journal $1998330909-914$.

17 Kobayashi S, Hirano T, Ozaki N, Fujita T \& Coupland RE. Functional differentiation within a single type of adrenal chromaffin cell. In Catecholamines: basic and clinical frontiers, pp 310-312. Eds I Usdin, IJ Kopin \& J Barchas. New York: Pergamon Press, 1979.

18 Suzuki T \& Kachi T. Similarities and differences in supporting and chromaffin cells in the mammalian adrenal medullae: an immunohistochemical study. Anatomical Record 1996244 358-365.

19 Wong DL. Why is the adrenal adrenergic? Endocrine Pathology $20031425-36$.

20 Glowniak JV, Kilty JE, Amara SG, Hoffman BJ \& Turner FE. Evaluation of metaiodobenzylguanidine uptake by the norepinephrine, 
dopamine and serotonin transporters. Journal of Nuclear Medicine 199334 1140-1146.

21 Gasnier B, Roisin MP, Scherman D, Coornaert S, Desplanches G \& Henry JP. Uptake of meta-iodobenzylguanidine by bovine chromaffin granule membranes. Molecular Pharmacology 198629 $275-280$

22 Kolby L, Bernhardt P, Levin-Jakobsen AM, Johanson V, Wangberg B, Ahlman H, Forssell-Aronsson E \& Nilsson $O$. Uptake of meta-iodobenzylguanidine in neuroendocrine tumours is mediated by vesicular monoamine transporters. British Journal of Cancer 200389 1383-1388.

23 Schroeter S, Apparsundaram S, Wiley RG, Miner LH, Sesack SR \& Blakely RD. Immunolocalization of the cocaine-and antidepressant-sensitive l-norepinephrine transporter. Journal of Comparative Neurology 2000420 211-232.

24 Cleary S, Brouwers F, Eisenhofer G, Pacak K, Christie DL, Lipski J, McNeil AR \& Phillips JK. Expression of the noradrenaline transporter and phenylethanolamine Nmethyltransferase in normal human adrenal gland and phaeochromocytoma. Cell and Tissue Research 200527 1-11 (Epub ahead of print).
25 Cell surface trafficking of the antidepressant-sensitive norepinephrine transporter revealed with an ectodomain antibody. Molecular and Cellular Neuroscience 200324 1131-1150.

26 Armour A, Cunningham SH, Gaze MN, Wheldon TE \& Mairs RJ. The efffect of cisplatin pretreatment on the accumulation of MIBG by neuroblatoma cells in vitro. British Journal of Cancer $1997 \mathbf{7 5}$ 470-476.

27 Boyd M, Mairs RJ, Keith WN, Ross SC, Welsh P, Akabani G, Owens J, Vaidyanathan G, Carruthers R, Dorrens J \& Zalutsky MR. An efficient targeted radiotherapy/gene therapy strategy utilising human telomerase promoters and radiostatine and harnessing radiation-mediated bystander effects. Journal of Gene Medicine 20046 937-947.

Received 29 April 2005

Accepted 21 June 2005 